\title{
Pericallosal lipoma in children: a rare case
}

\author{
Arushi Yadav, ${ }^{1}$ Jogender Kumar $^{2}$
}

${ }^{1}$ Department of Radiology, SMS Medical College and Hospital, Jaipur, Rajasthan, India ${ }^{2}$ Department of Neonatology, Post Graduate Institute of Medical Education and Research, Chandigarh, India

\section{Correspondence to} Dr Jogender Kumar, jogendrayadv1@gmail.com

Accepted 30 January 2018

\section{DESCRIPTION}

An 8-year-old developmentally normal boy was brought to emergency following a fall from a bicycle on the road. He could not remember how he fell and regained consciousness in about $5 \mathrm{~min}$. $\mathrm{He}$ had an abrasion on the right forearm and cheek. On neurological examination, he was fully conscious and alert with an orientation to time, place and person. There was no neurological deficit at the time of presentation in the emergency ward. The child was kept under observation. Two hours later, he experienced one episode of generalised tonic-clonic seizure which lasted for $3 \mathrm{~min}$. Seizures were managed as per standard protocol. CT scan of the brain was done (figure 1), which showed a
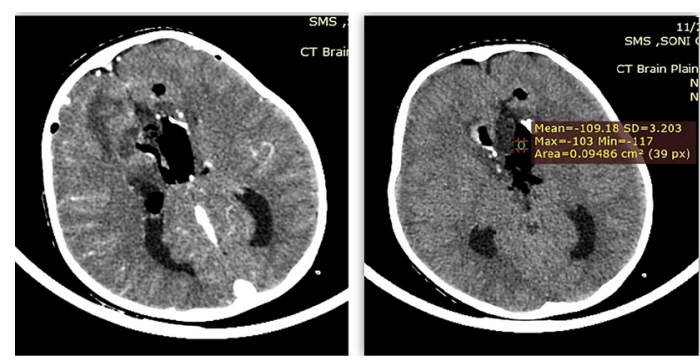

Figure 1 Brain CT (plain as well as contrast enhanced) - homogeneously hypodense midline lesion with a mean HU of -109 (fat) with bilateral ventricular and anterior subarachnoid extensions. A peripheral rim of calcification is seen.

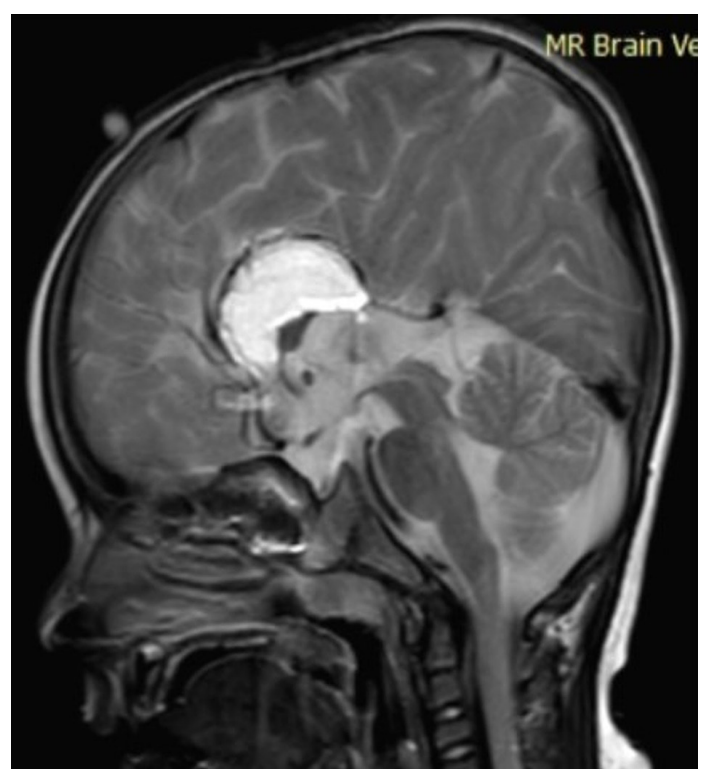

Figure 2 MRI brain (T2 image): well-defined hyperintense mass lesion situated in the midline just superior to the high riding third ventricle with nonvisualisation of the corpus callosum. homogeneously hypodense midline lesion with a mean HU of -109 (fat) with bilateral ventricular and anterior subarachnoid extensions. A peripheral rim of calcification was evident.

MRI brain was done subsequently to look for other structural malformations (figures 2-4), which showed a well-defined mass lesion situated in the midline superior to the high riding third ventricle having homogeneous hyperintensity on T1-weighted sequences as well as T2-weighted sequences. Bilateral lateral ventricles were oriented parallel with dilatation of occipital horns and agenesis of corpus callosum. These findings confirmed the diagnosis of 'tubulonodular pericallosal lipoma with corpus callosum agenesis' which is the most common variety of pericallosal lipoma. ${ }^{12}$
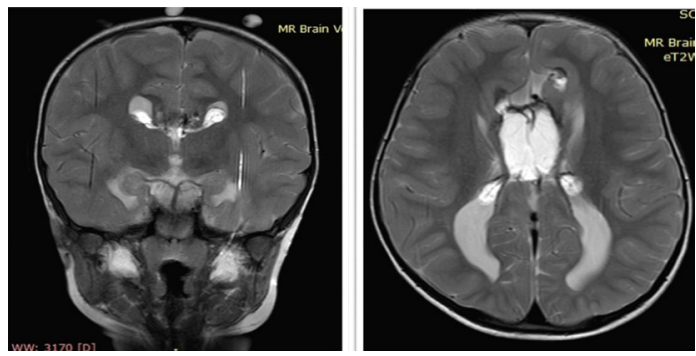

Figure 3 MRI brain (T2WI coronal reformatted image and axial image): hyperintense lesions in bilateral lateral ventricles with a stalk-like connection to the central hyperintense lesion.

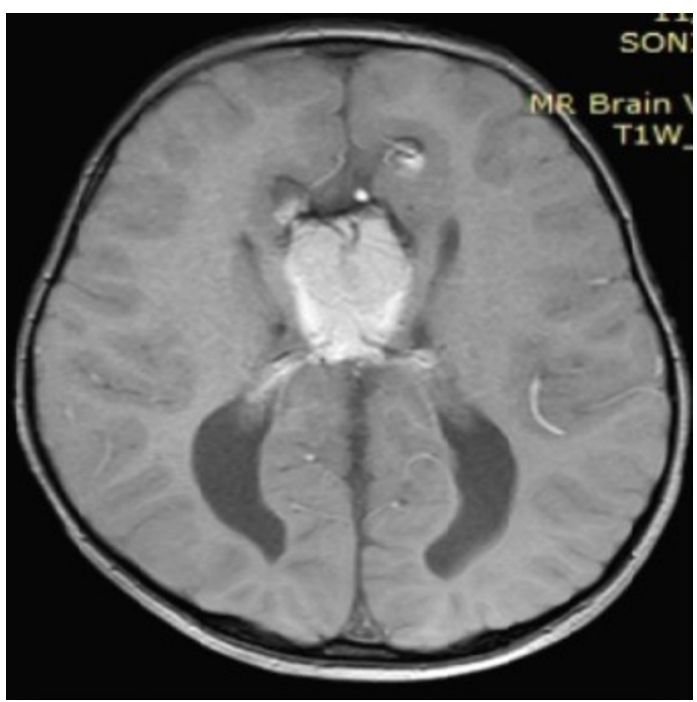

Figure 4 MRI brain (T1W image): hyperintense lesion with extensions in bilateral lateral ventricles and anterior subarachnoid spaces. Agenesis of corpus callosum present. 
The case was discussed with the paediatric neurologist and it was interpreted that corpus callosal lipoma would have incited

\section{Learning points}

Intracranial lipomas are extremely rare congenital malformation and account for $0.1-0.5 \%$ of all primary brain tumours. Pericallosal lipoma is the the most common variety of all intracranial lipomas (50\%) and is associated with varying degrees of dysgenesis/agenesis of corpus callosum like our index case.

- Pericallosal lipoma is of two types: tubulonodular type and curvilinear type. Tubulonodular type is characterised by a bulky mass that can be anterior or posterior in location, whereas, on the other hand, the curvilinear type is thin, long and often posterior in location. The tubulonodular type is more common.

- Nowadays, majority of pericallosal lipomas are prenatally detected.

- The radiographic findings (as described above) are very characteristic, and, therefore, pathognomonic.

- Isolated pericallosal lipomas are generally benign, selflimiting or slow-growing and remain asymptomatic in most of the cases. The overall prognosis of the corpus callosum lipoma is good. the seizure and the child had a fall with the transient loss of consciousness. Neurosurgery consultation was sought and as seizures were controlled by drugs, no urgent surgical intervention was indicated. Neurosurgical intervention is generally not required and it should be limited depending on the patient's symptoms, surgical feasibility, and associated malformations. ${ }^{34}$ The patient was discharged on antiepileptics.

Contributors $\mathrm{AY}$ and JK both were involved in case management and diagnosis of the case. Both were involved in writing the manuscript and literature review. Both approved the final draft.

Competing interests None declared.

Patient consent Obtained.

Provenance and peer review Not commissioned; externally peer reviewed.

(c) BMJ Publishing Group Ltd (unless otherwise stated in the text of the article) 2018. All rights reserved. No commercial use is permitted unless otherwise expressly granted.

\section{REFERENCES}

1 Chougar L, Blondiaux E, Moutard ML, et al. Variability of T1-weighted signal intensity of pericallosal lipomas in the fetus. Pediatr Radiol 2017. 10.1007/s00247-017-4028-1. [Epub ahead of print 28 Nov 2017].

2 Rahalkar AM, Rahalkar MD. Case report : 2 cases of lipoma of corpus callosum (LoCC) associated with lipoma of choroid plexus (LoCP). Indian I Radiol Imaging 2006:16:719.

3 Yilmaz N, Unal 0, Kiymaz N, et al. Intracranial lipomas--a clinical study. Clin Neurol Neurosurg 2006;108:363-8.

4 Yilmaz MB, Genc A, Egemen E, et al. Pericallosal Lipomas: A Series of 10 Cases with Clinical and Radiological Features. Turk Neurosurg 2016;26:364-8.

Copyright 2018 BMJ Publishing Group. All rights reserved. For permission to reuse any of this content visit http://group.bmj.com/group/rights-licensing/permissions.

BMJ Case Report Fellows may re-use this article for personal use and teaching without any further permission.

Become a Fellow of BMJ Case Reports today and you can:

- Submit as many cases as you like

- Enjoy fast sympathetic peer review and rapid publication of accepted articles

- Access all the published articles

- Re-use any of the published material for personal use and teaching without further permission

For information on Institutional Fellowships contact consortiasales@bmjgroup.com

Visit casereports.bmj.com for more articles like this and to become a Fellow 